\title{
Lithium borosulphate glasses: an analysis of glass transition temperature results
}

\author{
P R GANDHI, V K DESHPANDE* and K SINGH \\ Department of Physics, Nagpur University, Nagpur 440010, India \\ * Department of Physics, Visveraya Regional College of Engineering, Nagpur 440011, India
}

\begin{abstract}
Lithium borosulphate glasses have been prepared in three different series: (a) $(42.5-x) \mathrm{Li}_{2} \mathrm{O}: 57.5 \mathrm{~B}_{2} \mathrm{O}_{3}: x \mathrm{Li}_{2} \mathrm{SO}_{4}$; (b) $42.5 \mathrm{Li}_{2} \mathrm{O}:(57.5-x) \mathrm{B}_{2} \mathrm{O}_{3}: x \mathrm{Li}_{2} \mathrm{SO}_{4}$ and (c) $42 \cdot 5 \mathrm{Li}_{2} \mathrm{O}: 57 \cdot 5 \mathrm{~B}_{2} \mathrm{O}_{3}: x \mathrm{Li}_{2} \mathrm{SO}_{4}$. The glass transition temperature $\left(T_{g}\right)$ of these glasses has been analysed on the basis of the fraction of four coordinated boron which governs the glass structure. The analysis reveals that the addition of $\mathrm{Li}_{2} \mathrm{SO}_{4}$ in series (a) and (b) gives rise to increased value of $\mathrm{N}_{4}$ whereas, in series (c) it increases the number of non-bridging oxygens.
\end{abstract}

Keywords. Glass transition; four coordinated boron fraction; lithium borosulphate glasses.

\section{Introduction}

Lithium conducting glasses are used as solid electrolytes in electrochemical devices such as solid state batteries, coulometers, timers etc. In the last few decades a number of papers have been published on lithium borate (LB) glasses (Otto 1966; Takahashi and Yamamoto 1979; Levasseur et al 1979b; Button et al 1982; Ito et al 1983). The main interest in these glasses has been two-fold: (i) to understand the macroscopic structural details and (ii) to enhance the ionic conductivity of these glasses at the lowest possible temperature.

LB glasses are characterized by the boron network in their trigonal and tetragonal forms associated with the non-bridging oxygens (NBO's) (Bray and O'Keefe 1963). IR, NMR and Raman studies have been carried out on these glasses to understand the geometry and distribution of conduction sites responsible for ionic migration (Konijnedijk and Stevels 1975; Kamitsos et al 1987; Soppe et al 1988). Apart from the above studies, $T_{g}$ is the parameter that apparently gives the glass structure. This parameter and the conductivity results of LB glasses are found to be sensitive to the value of $\mathrm{N}_{4}$ for these glasses.

Ionic conductivity in glass can be enhanced by manipulating its structure either by controlling the thermal history or by increasing the mobile ion concentration (Charles 1966; Button et al 1983). Addition of lithium salts has also been reported to increase the ionic conductivity of lithium borate glasses (Levasseur et al 1979a; Singh and Rokade 1984; Deshpande et al 1985; Tuller and Button 1985; Gandhi et al 1989). The nature of incorporation of $\mathrm{LiCl}$ in $\mathrm{LB}$ glass system has been studied in detail (Button et al 1982) on the basis of NMR, Raman, IR and $T_{g}$ results. In this respect the role of lithium sulphate addition in LB glasses is still not well understood. Therefore in the present work a detailed analysis of the $T_{g}$ results has been carried out in lithium borosulphate glasses. 


\section{Experimental}

Otto (1966) reported that a glass with $42 \cdot 5 \quad \mathrm{Li}_{2} \mathrm{O}: 57 \cdot 5 \mathrm{~B}_{2} \mathrm{O}_{3}$ gives maximum conductivity in the LB series. This composition has been taken as a base system in the present study. Lithium borosulphate glasses have been prepared in the following three different series:

(a) $(42 \cdot 5-x) \mathrm{Li}_{2} \mathrm{O}: 57 \cdot 5 \mathrm{~B}_{2} \mathrm{O}_{3}: x \mathrm{Li}_{2} \mathrm{SO}_{4}$;

(b) $42 \cdot 5 \mathrm{Li}_{2} \mathrm{O}:(57 \cdot 5-x) \mathrm{B}_{2} \mathrm{O}_{3}: x \mathrm{Li}_{2} \mathrm{SO}_{4}$ and

(c) $42 \cdot 5 \mathrm{Li}_{2} \mathrm{O}: 57 \cdot 5 \mathrm{~B}_{2} \mathrm{O}_{3}: x \mathrm{Li}_{2} \mathrm{SO}_{4}$

where $x=3,5.7,10$ and $15 \mathrm{~mol}_{0}^{\circ} . \mathrm{B}_{2} \mathrm{O}_{3} \mathrm{AR}$ (purity $=99.9 \%$ ) (SISCO, India), $\mathrm{Li}_{2} \mathrm{CO}_{3}$ (purity $=99.9 \%$ ) (Moscow, Russia) and $\mathrm{Li}_{2} \mathrm{SO}_{4} \mathrm{AR}$ (purity $99.9 \%$ ) (SISCO, India) were used as starting materials. About $12 \mathrm{~g}$ of the raw material of each batch was weighed (with an accuracy of $0.01 \mathrm{mg}$ using a Mettler AE 163 balance) and mixed thoroughly under acetone. The dried mixture was heated up to the melting temperature in a platinum crucible at moderate rate. The melting temperature for these glasses was in the range 973 to $1173 \mathrm{~K}$ depending on the composition. The temperature was maintained at $40 \mathrm{~K}$ above the melting point for an hour to homogenize the melt. The glasses were cast by quenching the melt at room temperature between two aluminium blocks. The glass formation was confirmed by XRD and the transition temperatures estimated with a Perkin Elmer TADS 1700 unit, employing a scanning rate of $10^{\circ} \mathrm{C} / \mathrm{min}$.

\section{Results and discussion}

Figure 1 depicts the variation of $T_{q}$ as a function of $\mathrm{mol}^{\circ} \% \mathrm{Li}_{2} \mathrm{SO}_{4}$ for all the three series. It was observed that in series (a) $T_{9}$ decreases up to $3 \mathrm{~mol}_{\%}$ of $\mathrm{Li}_{2} \mathrm{SO}_{4}$ and remains constant with further increase in $\mathrm{Li}_{2} \mathrm{SO}_{4}$. For (b) $T_{g}$ decreases gradually with the increasing $\mathrm{Li}_{2} \mathrm{SO}_{4}$ content. Interestingly, in (c) a prominent decrease in $T_{9}$ is observed up to $10 \mathrm{~mol}_{\%}^{\%}$ of $\mathrm{Li}_{2} \mathrm{SO}_{4}$.

This variation of $T_{q}$ observed in three different series can be analysed on the basis of NMR and DTA results of LB glasses by Bray and O'Keefe (1963) who reported the fraction of four coordinated boron $\left(\mathrm{N}_{4}=\mathrm{BO}_{4} / \mathrm{BO}_{3}+\mathrm{BO}_{4}\right)$ and $T_{g}$ both are functions of $R=\mathrm{Li}_{2} \mathrm{O} / \mathrm{B}_{2} \mathrm{O}_{3}$ as shown in figures $2 \mathrm{a}$ and $2 \mathrm{~b}$ respectively. It has been assumed that

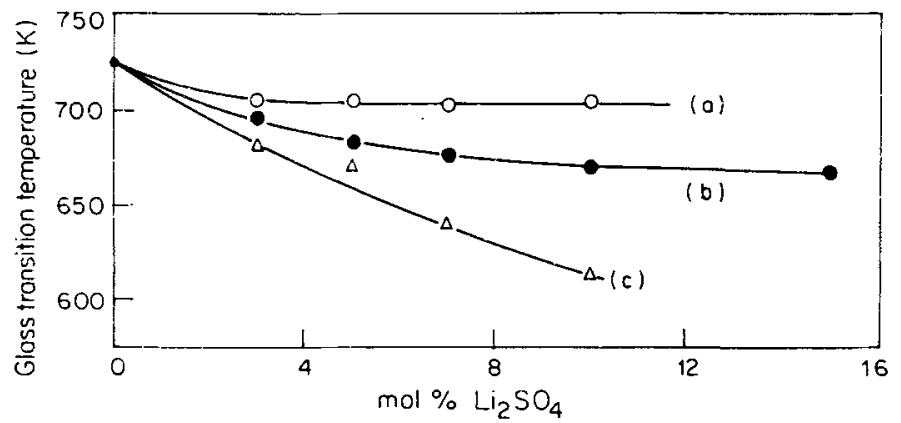

Figure 1. Variation of glass transition temperature with $\mathrm{mol}_{\%} \mathrm{Li}_{2} \mathrm{SO}_{4}$ for lithium borosulphate glasses. 

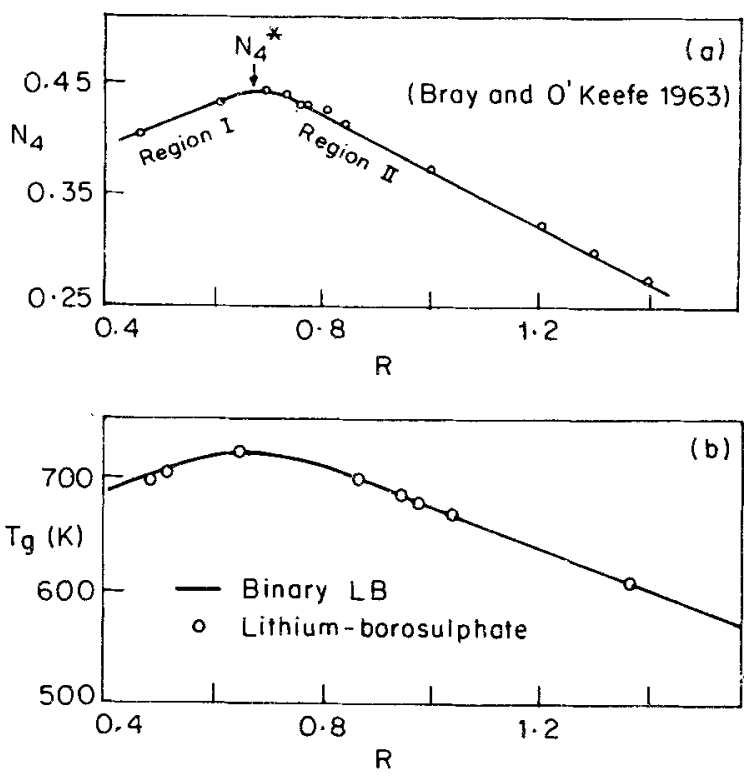

Figure 2a, b. Variation of fraction of four co-ordinated boron $\left(\mathrm{N}_{4}\right)$ and glass transition temperature for LB glasses.

Table 1. Composition, $R$, glass transition temperature, $\mathrm{N}_{4 \mathrm{~A}}, \mathrm{~N}_{4 \mathrm{~B}}$ and $\Delta \mathrm{N}_{4}$ for lithium borosulphate glasses.

\begin{tabular}{|c|c|c|c|c|c|}
\hline $\begin{array}{l}\text { Composition (in mol \%) } \\
\mathrm{Li}_{2} \mathrm{O}: \mathrm{B}_{2} \mathrm{O}_{3}: \mathrm{Li}_{2} \mathrm{SO}_{4}\end{array}$ & $R$ & $\begin{array}{c}T_{g} \\
(\text { in } \mathrm{K} \text { ) }\end{array}$ & $\mathrm{N}_{4 \mathrm{~A}}$ & $\mathrm{~N}_{4 \mathrm{~B}}$ & $\Delta \mathrm{N}_{4}$ \\
\hline $42 \cdot 5: 57 \cdot 5: 0$ & 0.73 & $726 \cdot 0$ & 0.442 & 0.442 & 0 \\
\hline $39 \cdot 5: 57 \cdot 5: 3$ & 0.68 & $704 \cdot 6$ & 0.446 & 0.415 & 0.031 \\
\hline $37 \cdot 5: 57 \cdot 5: 5$ & 0.65 & $704 \cdot 5$ & 0.441 & 0.415 & 0.026 \\
\hline $35 \cdot 5: 57 \cdot 5: 7$ & 0.61 & $702 \cdot 7$ & 0.43 & $0 \cdot 410$ & 0.02 \\
\hline $42 \cdot 5: 54 \cdot 5: 3$ & 0.77 & $698 \cdot 2$ & $0 \cdot 432$ & 0.41 & 0.022 \\
\hline $42 \cdot 5: 52 \cdot 5: 5$ & 0.80 & 683.8 & 0.425 & $0 \cdot 385$ & 0.04 \\
\hline $42 \cdot 5: 50 \cdot 5: 7$ & 0.84 & 678.8 & $0 \cdot 415$ & $0 \cdot 38$ & 0.035 \\
\hline $42 \cdot 5: 47 \cdot 5: 10$ & 0.89 & $670 \cdot 3$ & 0.402 & 0.365 & 0.037 \\
\hline $42 \cdot 5: 42 \cdot 5: 15$ & 1.00 & $669 \cdot 2$ & 0.375 & 0.365 & 0.01 \\
\hline $41 \cdot 225: 55 \cdot 775: 3$ & 0.73 & $681 \cdot 3$ & 0.442 & $0 \cdot 38$ & 0.062 \\
\hline $40 \cdot 375: 54 \cdot 625: 5$ & $0 \cdot 73$ & $669 \cdot 0$ & $0 \cdot 442$ & $0 \cdot 365$ & 0.077 \\
\hline $39 \cdot 525: 53 \cdot 475: 7$ & 0.73 & $641 \cdot 8$ & $0 \cdot 442$ & $0 \cdot 315$ & $0 \cdot 127$ \\
\hline $38 \cdot 25: 51 \cdot 75: 10$ & 0.73 & $612 \cdot 8$ & 0.442 & $0 \cdot 28$ & $0 \cdot 162$ \\
\hline
\end{tabular}

$\mathrm{N}_{4}$ for ternary glass system (i.e. glasses prepared in the present study) is also a function of $R$ and varies similarly as that for the binary LB glasses. Thus $\mathrm{N}_{4}$ for three series are calculated from figure $2 \mathrm{a}$ and denoted as $\mathrm{N}_{4 \mathrm{~A}}$.

The functional dependence of $T_{g}$ on $R$ for LB glasses follows that of $\mathrm{N}_{4}$ as can be seen from figure $2 \mathrm{~b}$. It is evident from this figure that the $T_{g}$ values for lithium borosulphate glasses (marked by open circles) lie on the same curve for LB glasses. Thus for a particular value of $T_{g}$, it is logical to calculate $R$ from figure $2 b$ and the corresponding $\mathrm{N}_{4}$ from figure 2a. $\mathrm{N}_{4}$ thus calculated are denoted by $\mathrm{N}_{4 B}$. The values of $\mathrm{N}_{4 \mathrm{~A}}, \mathrm{~N}_{4 \mathrm{~B}}$ along with those of $T_{g}$ and $R$ for different series are given in table 1 . The difference in values of 


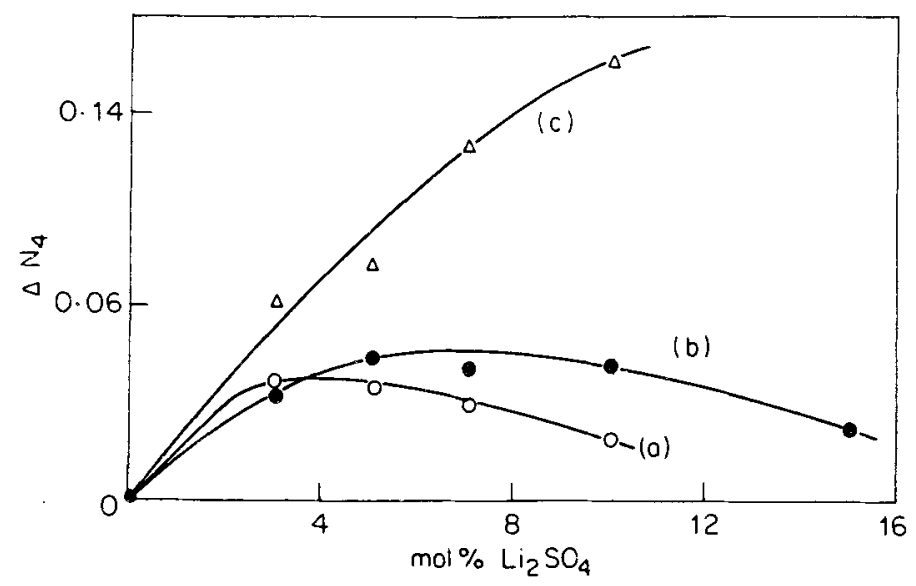

Figure 3. $\Delta \mathrm{N}_{4}$ variation with $\mathrm{mol}_{0}^{\circ} \mathrm{Li}_{2} \mathrm{SO}_{4}$.

$\mathrm{N}_{4}$ i.e. $\mathrm{N}_{4 \mathrm{~A}}$ and $\mathrm{N}_{4 \mathrm{~B}}$ suggests that the $\mathrm{N}_{4}$ is not only a function of $R$ but also gets influenced by $\mathrm{Li}_{2} \mathrm{SO}_{4}$. This is justified because, according to Kamitsos et al (1987), the incorporation of $\mathrm{Li}_{2} \mathrm{SO}_{4}$ in lithium borate glasses gives rise to polar groups viz. $\mathrm{BO}_{4}$ or NBO's. Thus it can be considered that the obtained $\mathrm{N}_{4 \mathrm{~B}}$ is the contribution of $\mathrm{Li}_{2} \mathrm{SO}_{4}$ to $\mathrm{N}_{4}$ for ternary glasses.

In order to understand the role of $\mathrm{Li}_{2} \mathrm{SO}_{4}$ in $\mathrm{LB}$ glasses and the $T_{9}$ variation in lithium borosulphate glasses (figure 1), the difference in the two $\mathrm{N}_{4}$ values $\Delta \mathrm{N}_{4}\left(\Delta \mathrm{N}_{4}=\mathrm{N}_{4 \mathrm{~A}}-\mathrm{N}_{4 \mathrm{~B}}\right)$ is plotted as a function of $\mathrm{mol} \%$ of $\mathrm{Li}_{2} \mathrm{SO}_{4}$ in figure 3 . The variation of $T_{g}$ in different series can be interpreted in the light of figures $2 \mathrm{a}$ and 3 as follows.

In figure $2 \mathrm{a}$, the maximum value of $\mathrm{N}_{4}$ (say $\mathrm{N}_{4}^{*}$ ) corresponds to $R=0.73$ (for $42 \cdot 5 \mathrm{Li}_{2} \mathrm{O}-57 \cdot 5 \mathrm{~B}_{2} \mathrm{O}_{3}$ composition). From this figure one can distinguish two regions of $\mathrm{N}_{4}$ : region-I on the left side of $\mathrm{N}_{4}^{*}$ where $\mathrm{N}_{4}$ decreases with decreasing $R$ and region-II on the right side of $\mathrm{N}_{4}^{*}$, where $\mathrm{N}_{4}$ decreases with increasing $R$. For series (a) with addition of $\mathrm{Li}_{2} \mathrm{SO}_{4}$ one moves in region-I (since $R<0.73$ ) and thus the corresponding $\mathrm{N}_{4}$ and $T_{g}$ should decrease. However, the observed result is not so. This has been attributed to the contribution of $\mathrm{N}_{4 \mathrm{~B}}$ due to the added $\mathrm{Li}_{2} \mathrm{SO}_{4}$ which strengthens the glass structure and hence enhances the $T_{g}$. It is also evident from figure 3 that the $\Delta \mathrm{N}_{4}$ increases for $3 \mathrm{~mol}_{\%} \mathrm{Li}_{2} \mathrm{SO}_{4}$ but then decreases with further increase in $\mathrm{Li}_{2} \mathrm{SO}_{4}$. Thus the contribution of $\mathrm{N}_{4 \mathrm{~B}}$ is less for $3 \mathrm{~mol}_{\%} / \mathrm{Li}_{2} \mathrm{SO}_{4}$ and it increases with further addition of $\mathrm{Li}_{2} \mathrm{SO}_{4}$. This explains the observed results for series (a).

In case of series (b) with the addition of $\mathrm{Li}_{2} \mathrm{SO}_{4}$ one moves to the right of $\mathrm{N}_{4}^{*}(R>0.73)$ in region-II, hence again $\mathrm{N}_{4}$ and $T_{g}$ should decrease. A critical look at figure 2 a reveals that the fall in $\mathrm{N}_{4}$ and $T_{g}$ for series (b) should be of higher magnitude than that for series (a), since the slope in region-II is greater than in region-I. From figure 3 it can be seen that $\Delta \mathrm{N}_{4}$ increases for this series i.e. $\mathrm{N}_{4 \mathrm{~B}}$ in this case is less than that in series (b). Thus the gradual decrease in $T_{g}$ for this series can be understood. In this series for $15 \mathrm{~mol} \%$ of $\mathrm{Li}_{2} \mathrm{SO}_{4}$ the $\Delta \mathrm{N}_{4}$ decreases compared to that for $10 \mathrm{~mol} \% \mathrm{Li}_{2} \mathrm{SO}_{4}$. Hence the $T_{g}$ for 10 and $15 \mathrm{~mol}_{\%} / \mathrm{Li}_{2} \mathrm{SO}_{4}$ containing glasses are almost the same. This also means that for the glass with $15 \mathrm{~mol}_{0}^{\circ} \mathrm{Li}_{2} \mathrm{SO}_{4}$ the contribution of $\mathrm{N}_{4 \mathrm{~B}}$ has increased maintaining the same $T_{g}$. 
For series (c), with addition of $\mathrm{Li}_{2} \mathrm{SO}_{4}, R$ remains constant at $\mathrm{N}_{4}^{*}$. A prominent decrease in $T_{g}$ observed in this case can be understood on the basis of a remarkable enhancement in $\Delta \mathrm{N}_{4}$ (figure 3). This suggests that the addition of $\mathrm{Li}_{2} \mathrm{SO}_{4}$ does not contribute much to $\mathrm{N}_{4 \mathrm{~B}}$. On the other hand it may increase the NBO's and thereby decrease $T_{g}$ drastically.

\section{Conclusion}

On the basis of the analysis of $T_{g}$ results of lithium borosulphate glasses the following conclusions can be drawn:

(i) When $\mathrm{Li}_{2} \mathrm{SO}_{4}$ is substituted for $\mathrm{Li}_{2} \mathrm{O}$ (not site to site) (series a) and $\mathrm{B}_{2} \mathrm{O}_{3}$ (series b) in $\mathrm{LB}$ glasses it contributes to the formation of four coordinated boron.

(ii) The number of four-coordinated boron contributed by $\mathrm{Li}_{2} \mathrm{SO}_{4}$ is more in series (a) than in series (b). Hence the variation of $T_{g}$ in series (a) is less than that in (b).

(iii) When $\mathrm{Li}_{2} \mathrm{SO}_{4}$ is added to $\mathrm{LB}$ glasses by keeping $\mathrm{Li}_{2} \mathrm{O} / \mathrm{B}_{2} \mathrm{O}_{3}$ ratio constant (series c) it gives rise to NBO's which lowers $T_{g}$ drastically.

\section{References}

Bray P J and O'Keefe J G 1963 Phys. Chem. Glasses 437

Button D P, Tandon R P, King C, Velez M H, Tuller H L and Uhlmann D R 1982 J. Non-Cryst. Solids 49129

Button D P, Moon P K, Tuller H L and Uhlmann D R 1983 Glastech. Ber. 56 K Bd 2856

Charles R J 1966 J. Am. Ceram. Soc. 4955

Deshpande V K, Rokade S and Singh K 1985 Proc. Sixth Riso. Int. Symp. on transport-structure relationship in fast ion and mixed conductors, Denmark (eds) F W Poulsen, N H Andersen, K Clusen, S Skaarup and O T Sorensen; GH-Tryk 1/S Odense, 129

Gandhi P R, Deshpande V K and Singh K 1989 Solid State Ionics 3697

Ito Y, Miyauchi K and Oi T 1983 J. Non-Cryst. Solids 57389

Konijnedijk W N and Stevels J M 1975 J. Non-Cryst. Solids 18307

Kamitsos E I, Kavakassites M A and Chryssikos G D 1986 J. Phys. Chem. 904528

Kamitsos E I, Kavakassites M A and Chryssikos G D 1987 J. Phys. Chem. 915807

Levasseur A, Kabala M, Brethous J C and Hagenmullar P 1979a Solid State Commun. 32839

Levasseur A, Brethous J C, Reau J M and Hagenmullar P 1979b Mater. Res. Bull. 14921

Otto K 1966 Phys. Chem. Glasses 729

Singh K and Rokade S 1984 J. Power Sources 13159

Soppe W, Marcel C V D and Hartog H W D 1988 J. Non-Cryst. Solids 101101

Takahashi $T$ and Yamamoto $O 1979$ Chem. Lett. 135

Tuller H L and Button D P 1985 Proc. Sixth Riso. Int. Symp. on Transport-structure relationship in fast ion and mixed conductors, Denmark (eds) F W Poulsen, N H Andersen, K Clusen, S Skaarup and O T Sorensen; GH-Tryk 1/S Odense, 119 